\title{
Relationship between Oxygen Defects and Properties of Scandium Oxide Films Prepared by Ion-Beam Sputtering
}

\author{
Pengfei Kong ${ }^{1,2}$, Yunti Pu ${ }^{2, *}$, Ping $\mathrm{Ma}^{2}$ and Jiliang $\mathrm{Zhu}{ }^{1, *}$ \\ 1 Physical Chemistry of Materials, College of Materials Science and Engineering, Sichuan University, \\ Chengdu 610064, China \\ 2 Fine Optical Engineering Research Center, Chengdu 610041, China \\ * Correspondence: cdpyt@163.com (Y.P.); jlzhu167@scu.edu.cn (J.Z.)
}

Received: 18 July 2019; Accepted: 13 August 2019; Published: 15 August 2019

\begin{abstract}
Scandium oxide $\left(\mathrm{Sc}_{2} \mathrm{O}_{3}\right)$ thin films with different numbers of oxygen defects were prepared by ion-beam sputtering under different oxygen flow rates. The results showed that the oxygen defects heavily affected crystal phases, optical properties, laser-induced damage threshold (LIDT) and surface quality of $\mathrm{Sc}_{2} \mathrm{O}_{3}$ films. The thin film under 0 standard-state cubic centimeter per minute $(\mathrm{sccm})$ oxygen flow rate had the largest number of oxygen defects, which resulted in the lowest transmittance, LIDT and the worst surface quality. In addition, the refractive index of $0 \mathrm{sccm} \mathrm{Sc}_{2} \mathrm{O}_{3}$ film could not be measured in the same way. When the oxygen flow rate was $15 \mathrm{sccm}$, the $\mathrm{Sc}_{2} \mathrm{O}_{3}$ film possessed the best transmittance, refractive index, LIDT and surface roughness due to the lowest number of oxygen defects. This work elucidated the relationship between oxygen defects and properties of $\mathrm{Sc}_{2} \mathrm{O}_{3}$ films. Controlling oxygen flow rate was an important step of limiting the number of oxygen defects, which is of great significance for industrial production.
\end{abstract}

Keywords: scandium oxide thin films; ion-beam sputtering; oxygen flow rates; oxygen defects; properties

\section{Introduction}

Scandium oxide $\left(\mathrm{Sc}_{2} \mathrm{O}_{3}\right)$ is an important kind of optical compound and is considered to be one of the most promising optical materials due to the high refractive index in the UV wavelength range [1-3]. Moreover, it has high damage resistance to laser irradiation, which is of high importance for high-power laser applications $[2,4,5]$. A wide band gap is another characteristic of $\mathrm{Sc}_{2} \mathrm{O}_{3}$, which linearly correlates with the laser-induced damage threshold [6]. With these advantages, various applications of $\mathrm{Sc}_{2} \mathrm{O}_{3}$ films have been achieved, such as quarter-wave stacks [2], antireflection coatings for high-power UV lasers [2,7], high-reflection multilayer coatings in light-emitting diodes (LEDs) [2] and resist materials in electron beam lithography [8].

There are many methods for the deposition of $\mathrm{Sc}_{2} \mathrm{O}_{3}$ films, such as thermal oxidation of freshly evaporated scandium [9], electron beam evaporation (EBE) [10,11], atomic layer deposition (ALD) [12,13], molecular beam epitaxy [14], chemical vapor deposition (CVD) [15,16], pulsed laser deposition [17], high pressure sputtering [18], radio frequency (RF) magnetron sputtering of $\mathrm{Sc}_{2} \mathrm{O}_{3}$ target [19] and reactive magnetron sputtering (RMS) of Sc metal target [20]. As one of the important methods for the preparation of thin films, ion-beam sputtering (IBS) has its own unique advantages. The technique of IBS can be applied to high-melting-point materials. IBS opens up new routes for the accurate control of transmittance and refractive index of film. In addition, thin films prepared by IBS technique possess higher surface quality and ultralow loss in comparison with other deposition techniques. 
Recently, a major problem has attracted great attention during the IBS deposition process. The oxidation degree of the growing layer is changed because of different oxygen flow rates [21]. In this case, oxygen defects will be formed in films. Krous et al. [22] indicated that there are oxygen defects in $\mathrm{Sc}_{2} \mathrm{O}_{3}$ films deposited by IBS. Langston et al. [3] shown that a correlation exists between the oxygen interstitials in $\mathrm{Sc}_{2} \mathrm{O}_{3}$ films and optical absorption in the films. Fu et al. [5] studied the laser-induced damage of $\mathrm{Sc}_{2} \mathrm{O}_{3}-\mathrm{SiO}_{2}$ mixtures for sub-picosecond pulses. These studies do not fully reveal the influence of oxygen defects on $\mathrm{Sc}_{2} \mathrm{O}_{3}$ films. As one of the most promising optical films, optical properties (transmittance and refractive index) of $\mathrm{Sc}_{2} \mathrm{O}_{3}$ thin films are very important in practical applications. Moreover, laser-induced damage threshold (LIDT) is also of great significance, representing the resistance ability of optical materials for laser beam. However, up to now, no effort has been made to study the influence of oxygen defects formed during the preparation process of $\mathrm{Sc}_{2} \mathrm{O}_{3}$ films by IBS on the optical performances and LIDT $(355 \mathrm{~nm})$ irradiated by the laser beams with the pulses width of $9.2 \mathrm{~ns}$ full width at half maximum (FWHM) in the nanosecond regime.

In this work, $\mathrm{Sc}_{2} \mathrm{O}_{3}$ thin films are prepared by the IBS technique. During the preparation process, varied oxygen flow rates are used to produce different numbers of oxygen defects in films. The purpose of this work is to compare the peak shifts of crystal phases, optical performances, LIDT ( $355 \mathrm{~nm}$ ) and surface quality of $\mathrm{Sc}_{2} \mathrm{O}_{3}$ films under different oxygen flow rates. The comparison aims to discover the effect of oxygen defect on the properties of $\mathrm{Sc}_{2} \mathrm{O}_{3}$ films, which can give guidance for the preparation of high-quality $\mathrm{Sc}_{2} \mathrm{O}_{3}$ films in actual production.

\section{Experimental Details}

\subsection{Sample Preparation}

Conventional cleaning procedures were taken before the substrates were put into coating chamber. $\mathrm{Sc}_{2} \mathrm{O}_{3}$ films were deposited on $\mathrm{SiO}_{2}$ substrates by IBS, as shown in Figure 1a. The base pressure was below $5 \times 10^{-7}$ Torr and created by the coating equipment, which was a combination of a mechanical pump and a cryopump. The chamber volume was $1000 \mathrm{~L}$. The pumping speed of the cryopump was $10,000 \mathrm{~L} / \mathrm{s}$ and would determine the oxygen residence time, which was the intrinsic property and would determine the film composition. A target of $\mathrm{Sc}_{2} \mathrm{O}_{3}$ with $99.99 \%$ purity was sputtered by a radio-frequency ion source with Ar gas. The target power density $6.5 \mathrm{~W} / \mathrm{cm}^{2}$ and the Ar flow rate was $20 \mathrm{sccm}$. In addition, the deposition rate of $\mathrm{Sc}_{2} \mathrm{O}_{3}$ films was $0.06 \mathrm{~nm} / \mathrm{s}$, and the thickness of films was $200 \mathrm{~nm}$, which was controlled by an in situ broadband optical monitoring system. During the deposition process, different oxygen flow rates $(0,15,25,35$ and $45 \mathrm{sccm})$ were used to produce different numbers of oxygen defects in films, and an active feedback control system was used to control oxygen flow rates. In this research, all gases used for deposition were over $99.999 \%$ purity.
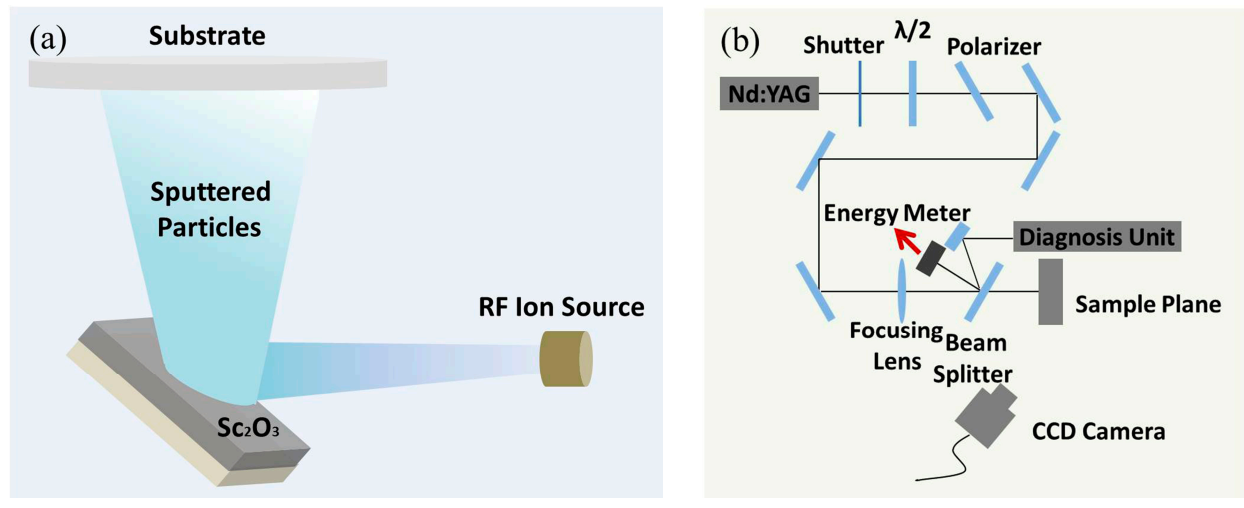

Figure 1. (a) Schematic diagram of ion-beam sputtering setup; (b) Schematic layout of damage test system. 


\subsection{Film Characterization}

The elemental composition of films was investigated by X-ray photoelectron spectroscopy (XPS) using a XSAM800 spectrometer (Shimadzu, Kyoto, Japan). In order to reduce test errors, the peak positions of elements were calibrated from the hydrocarbon contamination using the $\mathrm{C} 1 \mathrm{~s}$ peak at $284.6 \mathrm{eV}$, which is usually used as standard peak position in XPS spectra. All $\mathrm{Sc}_{2} \mathrm{O}_{3}$ thin films were treated by $\mathrm{Ar}^{+}$ions bombardment in order to eliminate contributions of surface contamination by organic compounds and atmospheric oxidation [22].

To determine crystal phase composition of films, X-ray diffraction (XRD) measurements of samples were performed using an EMPYREAN diffractometer (Panalytical, Almelo, Netherlands). The grazing incidence (GIXRD) method was used in a $2 \theta$ range of $20^{\circ}$ to $55^{\circ}$. The angle between the collimated $\mathrm{X}$-ray beam and the sample surface was adjusted to $0.5^{\circ}$.

Optical constants (absorption coefficients and band gaps) were determined from transmittance spectra. The transmittance spectra were measured by spectrophotometric technique (PerkinElmer's Lambda 950 spectrophotometer, Waltham, MA, USA). The refractive index spectra were measured by GES-5E ellipsometer (Semilab, Budapest, Hungary).

Laser damage resistance of films under irradiation had been tested by one-on-one mode, as shown in Figure 1b. In brief, the beam (9.2 ns FWHM) generated from a $355 \mathrm{~nm} \mathrm{Nd:YAG} \mathrm{laser} \mathrm{was} \mathrm{focused}$ to form a $0.15 \mathrm{~mm}$ 1/e diameter spot on every film plane. One hundred different sites were chosen with an interval of $2 \mathrm{~mm}$ on each sample plane. Each site was irradiated with 200 pulses $(1 \mathrm{~Hz})$. After irradiation, every site was examined to detect the extent of damage by optical microscope. The ratio of the damage sites to all sites at certain energy was used as the damage probability at this certain energy. The zero-damage probability ( $X$-axis intersection) was obtained by linear extrapolation of the damage probability data, and then it was used as the LIDT.

The surface quality of each film was imaged using atomic force microscopy (AFM, Bruker, Karlsruhe, Germany), over a $5 \times 5 \mu \mathrm{m}^{2}$ scan area. The root mean square of surface roughness, $R_{\mathrm{q}}$, was obtained from the AFM image.

\section{Results}

The XPS study was performed in order to examine the stoichiometry of $\mathrm{Sc}_{2} \mathrm{O}_{3}$ films. The high-resolution XPS spectra of $\mathrm{O} 1 s$ and the atomic percent of oxygen defect are shown in Figure 2. For each $\mathrm{Sc}_{2} \mathrm{O}_{3}$ film, the presence of $\mathrm{O} 1 \mathrm{~s}$ peaks at different chemical shifts suggests that the $\mathrm{O}$ atoms have two types of chemical environment. The peak for $E_{\mathrm{b}}$ at $529.7 \mathrm{eV}$ corresponds to Sc-O-Sc, and the peak for $E_{\mathrm{b}}$ at $531.2 \mathrm{eV}$ corresponds to oxygen atom of oxygen defect. The atomic percent of each $\mathrm{O}$ atom is calculated using the area of $\mathrm{O} 1 \mathrm{~s}$ peak [23]. Through analysis of the area of oxygen defect, it is found that the number of oxygen defects decreases sharply at first. When oxygen flow rate is over $15 \mathrm{sccm}$, oxygen defect increases slowly with the increase of oxygen flow rate.

The XRD patterns taken from $\mathrm{Sc}_{2} \mathrm{O}_{3}$ films under different oxygen flow rates are presented in Figure 3a. The peaks appearing in the XRD profiles can be indexed to the (222) and (440) planes of $\mathrm{Sc}_{2} \mathrm{O}_{3}$. For the amorphous metal oxide, phase formation is easy with a small amount of oxygen from residual atmosphere in the deposition chamber [24,25] because $\mathrm{Sc}_{2} \mathrm{O}_{3}$ has large standard molar enthalpy of formation $(-1908.8 \mathrm{~kJ} / \mathrm{mol})$ indicating $\mathrm{Sc}_{2} \mathrm{O}_{3}$ has a strong oxygen affinity [26]. Moreover, the positions of (222) and (440) peaks in $0 \mathrm{sccm}$ sample shift towards smaller angles, which is correlated with increased compressive stress caused by oxygen defects. Oxygen defects include oxygen vacancies and interstitial oxygen. Oxygen vacancies will produce tensile stress, which will shrink lattice and increase angles of peaks. Interstitial oxygen will produce compressive stress, which will expand lattice and decrease angles of peaks. In this experiment, compressive stress created by interstitial oxygen is much larger than tensile stress produced by oxygen vacancies, so the stress in samples is compressive 
stress which causes the positions of (222) and (440) peaks to shift towards smaller angles. Compressive stress in films can be evaluated by the Atkinson formula [27]:

$$
\sigma_{\mathrm{f}}=\frac{E_{\mathrm{s}}}{6\left(1-\gamma_{\mathrm{s}}\right)} \cdot \frac{t_{\mathrm{s}}^{2}}{t_{\mathrm{f}}} \cdot\left(\frac{1}{R_{2}}-\frac{1}{R_{1}}\right)
$$

where $t_{\mathrm{s}}$ and $t_{\mathrm{f}}$ are the thickness of the substrate and film, respectively. $R_{1}$ and $R_{2}$ are radius of curvature before and after deposition, respectively. $E_{\mathrm{s}}$ is the Young's modulus, and $\gamma_{\mathrm{s}}$ is the Poisson coefficient of the fused silica substrate.
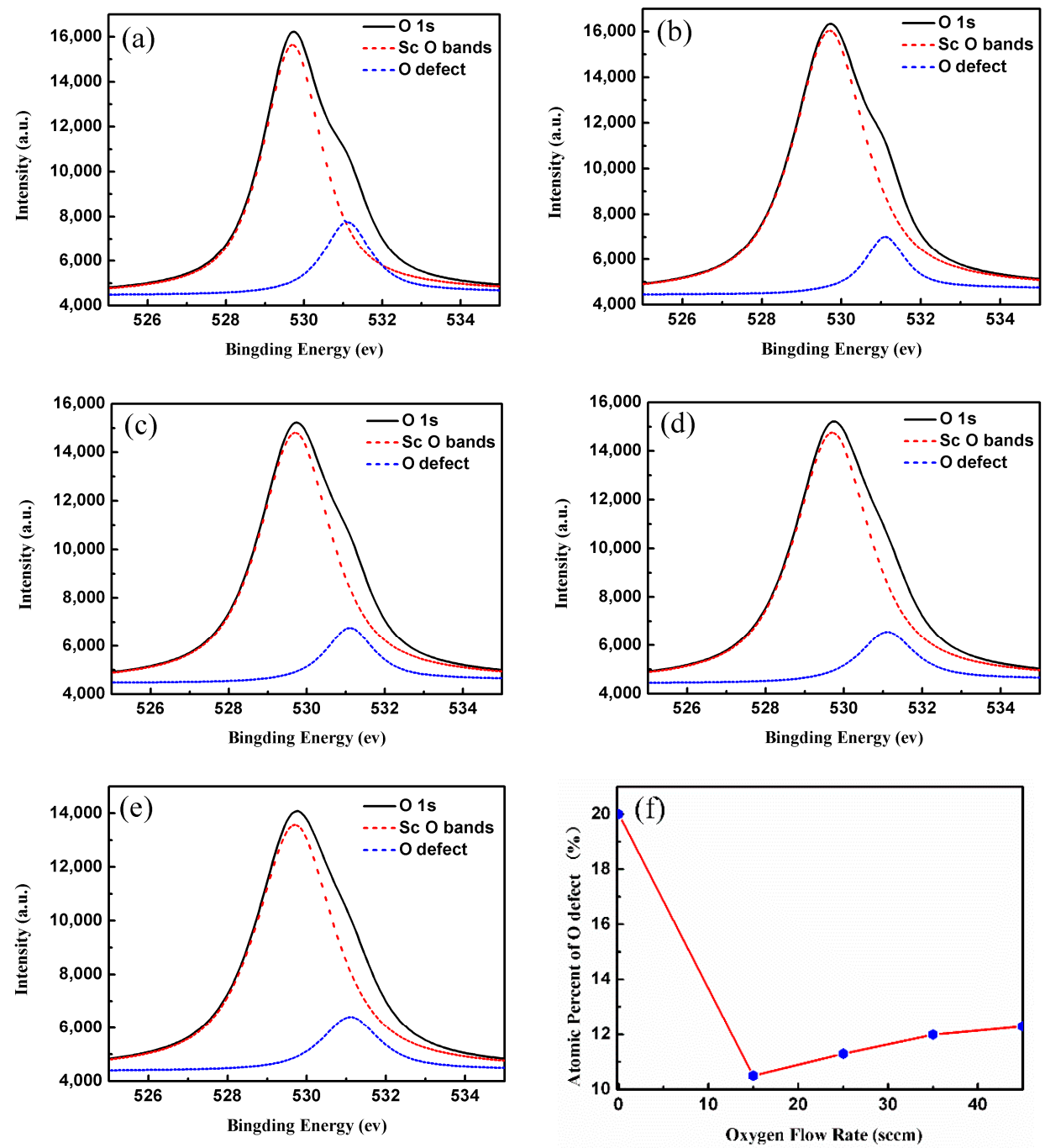

Figure 2. XPS spectra of $\mathrm{Sc}_{2} \mathrm{O}_{3}$ films and the atomic percent of oxygen defect under different oxygen flow rates: (a) $0 \mathrm{sccm}$; (b) $15 \mathrm{sccm}$; (c) $25 \mathrm{sccm}$; (d) $35 \mathrm{sccm}$; and (e) $45 \mathrm{sccm}$; (f) Atomic percent of oxygen defect.

Transmittance spectra of $\mathrm{Sc}_{2} \mathrm{O}_{3}$ thin films under different oxygen flow rates are given in Figure 4a. It is found that when oxygen flow rate is less than $15 \mathrm{sccm}$, transmittance increases with the increase of oxygen flow rate. When oxygen flow rate is higher than $15 \mathrm{sccm}$, transmittance of films does not change obviously. Such a result proved that transmittance of $\mathrm{Sc}_{2} \mathrm{O}_{3}$ thin films is associated with oxygen flow rate. Figure $4 \mathrm{~b}$ is refractive index spectra of $\mathrm{Sc}_{2} \mathrm{O}_{3}$ films prepared under different oxygen flow rates. In order to improve the test accuracy of refractive index, five samples are measured at each oxygen flow rate, and the reproducibility of refractive index is 1 . On the whole, refractive indexes of $\mathrm{Sc}_{2} \mathrm{O}_{3}$ films under different oxygen flow rates are similar, although the refractive index of $\mathrm{Sc}_{2} \mathrm{O}_{3}$ film under 
25 oxygen flow rate is slightly higher than those of others. The refractive index of $\mathrm{Sc}_{2} \mathrm{O}_{3}$ film under $0 \mathrm{sccm}$ has not been shown here due to the fact that its refractive index cannot be obtained in the same way. Free electrons in films are trapped by oxygen defects (vacancies) to form $\mathrm{F}$ and $\mathrm{F}^{+}$centers [28]. An $\mathrm{F}$ center is equivalent to a pair of electrons in combination with an oxygen vacancy, and an $\mathrm{F}^{+}$ center is the sum of an electron and a vacancy, so more $\mathrm{F}$ and $\mathrm{F}^{+}$centers will form when more oxygen defects are formed in films. The $\mathrm{F}$ and $\mathrm{F}^{+}$center located in films make materials strongly absorbent (see Figure 5a), which heavily affects transmittance and refractive index of thin films. This is the reason why the transmittance of film under 0 oxygen flow rate is much lower than that of other samples, and the refractive index of thin film under $0 \mathrm{sccm}$ flow rate cannot be obtained in the same way.
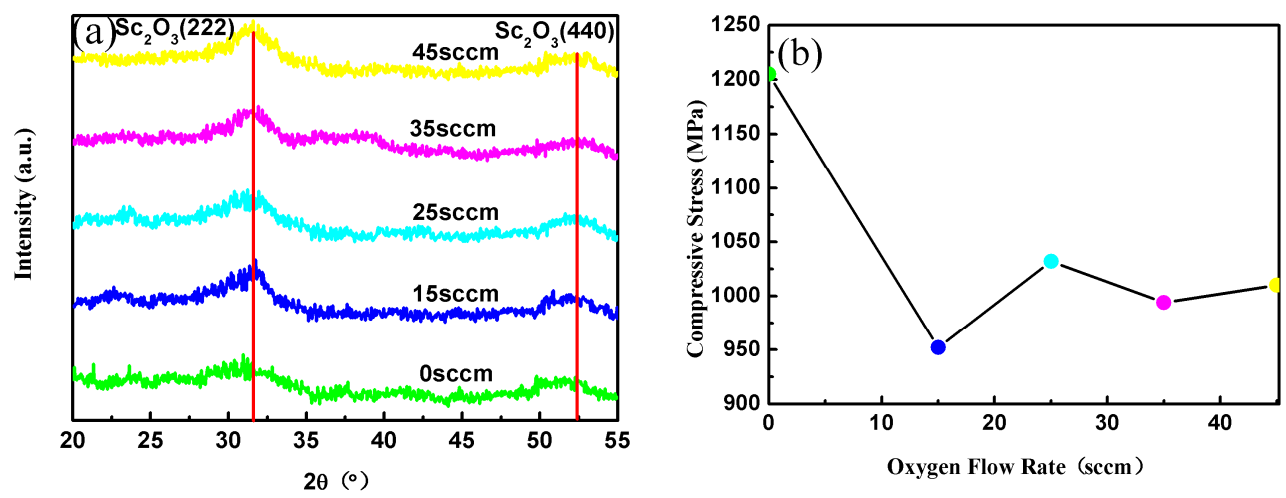

Figure 3. (a) X-ray diffraction spectra of $\mathrm{Sc}_{2} \mathrm{O}_{3}$ films deposited under different oxygen flow rates; (b) Compressive stress in $\mathrm{Sc}_{2} \mathrm{O}_{3}$ films under different oxygen flow rates.
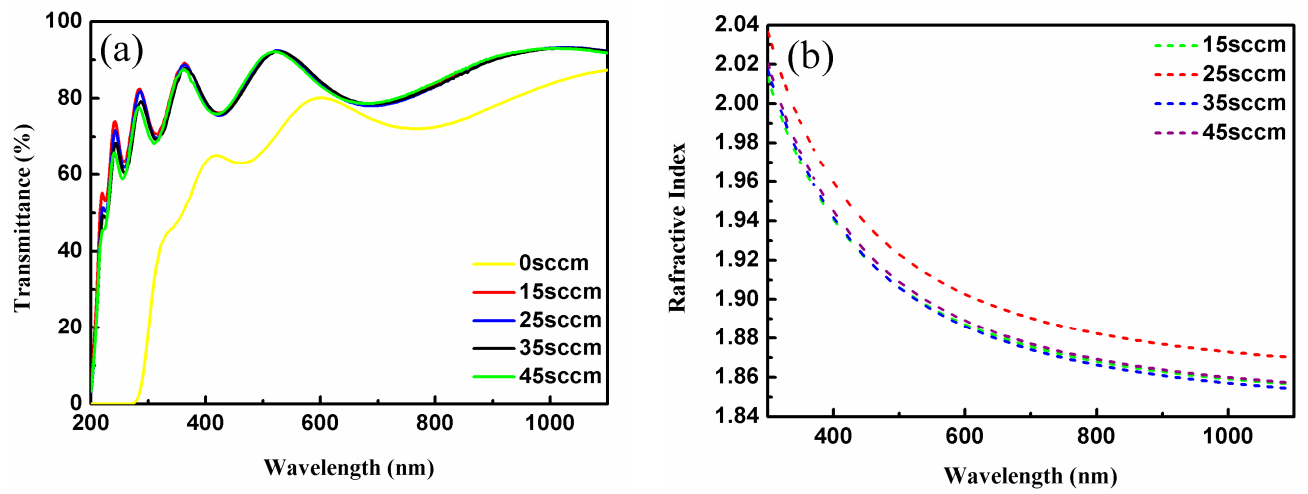

Figure 4. (a) Transmittance spectra of $\mathrm{Sc}_{2} \mathrm{O}_{3}$ films deposited under different oxygen flow rates; (b) Refractive index spectra of $\mathrm{Sc}_{2} \mathrm{O}_{3}$ films deposited under different oxygen flow rates.
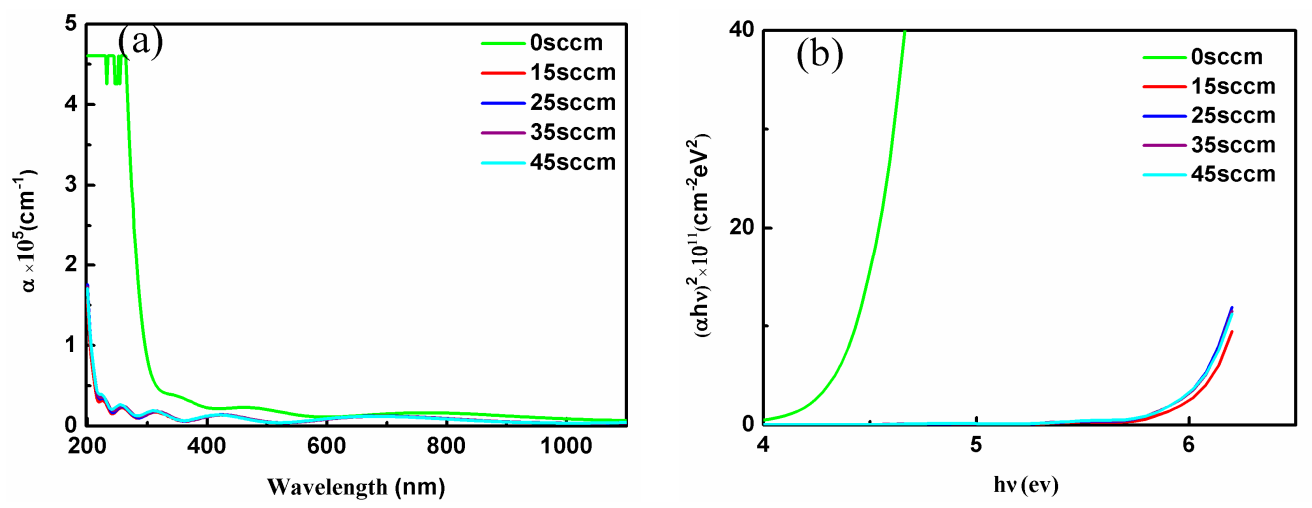

Figure 5. (a) Absorption coefficients of $\mathrm{Sc}_{2} \mathrm{O}_{3}$ films deposited under different oxygen flow rates; (b) Band gaps of $\mathrm{Sc}_{2} \mathrm{O}_{3}$ films deposited under different oxygen flow rates. 
LIDTs of $\mathrm{Sc}_{2} \mathrm{O}_{3}$ films under different oxygen flow rates have been tested by one-on-one. The results of one-on-one tests are given in Table 1. The LIDT of $\mathrm{Sc}_{2} \mathrm{O}_{3}$ film under $15 \mathrm{sccm}$ oxygen flow rate is the highest up to $7.2 \mathrm{~J} / \mathrm{cm}^{2}$. However, the LIDT of $\mathrm{Sc}_{2} \mathrm{O}_{3}$ film under $0 \mathrm{sccm}$ oxygen flow rate is below $1 \mathrm{~J} / \mathrm{cm}^{2}$. The findings confirm that LIDT of the sample is closely related to oxygen flow rate and oxygen defect. Before elaborating on the effect of oxygen defect on LIDT, the band gaps of all samples are calculated firstly using the following equation [29]:

$$
\alpha h v=A\left(h v-E_{\mathrm{g}}\right)^{m}
$$

where $\alpha$ is the absorption coefficient, $A$ is a constant, $h v$ is photon energy, $E_{\mathrm{g}}$ is the calculated band gap, and $m$ is $1 / 2,2$ or $3 / 2$, which depends on the nature of band gap: Direct, indirect or forbidden, respectively [30]. The absorption coefficient, $\alpha$, is obtained using the following equation [31]:

$$
\alpha=-\frac{\operatorname{In}(T)}{d}
$$

where $d$ is the physical thickness of films and $T$ is the transmittance. The absorption coefficients of $\mathrm{Sc}_{2} \mathrm{O}_{3}$ films under different oxygen flow rates are shown in Figure 5a. In the prepared films, the optical absorption coefficients are found to be greater than $10^{5} \mathrm{~cm}^{-1}$, which is consistent with the direct band gap.

Table 1. Laser-induced damage thresholds of $\mathrm{Sc}_{2} \mathrm{O}_{3}$ films deposited under different oxygen flow rates.

\begin{tabular}{cc}
\hline Oxygen Flow Rates $(\mathbf{s c c m})$ & LIDT $\left(\mathbf{J} / \mathbf{c m}^{\mathbf{2}}\right)$ \\
\hline 0 & 0.8 \\
15 & 7.2 \\
25 & 5.6 \\
35 & 5.3 \\
45 & 5.5 \\
\hline
\end{tabular}

Figure $5 \mathrm{~b}$ shows the calculated band gaps of different samples. The $0 \mathrm{sccm}$ sample has the lowest band gap of $4.52 \mathrm{eV}$, whereas the $15 \mathrm{sccm}$ sample has the highest band gap of $6.05 \mathrm{eV}$. Both band gaps of $25 \mathrm{sccm}$ and $35 \mathrm{sccm}$ samples are $6.01 \mathrm{eV}$, and $45 \mathrm{sccm}$ sample also has a higher band gap of $6.00 \mathrm{eV}$.

Previous studies have shown that the LIDT of optical film linearly correlates with the band gap of the film [6]. Therefore, film with a wider band gap possesses a higher LIDT. On the other hand, the differences of band gaps are derived from oxygen vacancies. In the experiment, there are some nanoprecursors in samples, and the nanoprecursors are derived from the partially oxidized scandium clusters related to oxygen content, oxygen residence time and many other factors. The nanoprecursors of scandium clusters can provide free electrons in films, but oxygen vacancies will capture electrons in films, which causes a decrease in the concentration of electrons. According to Burstein-Moss (BM) shift [32]:

$$
\Delta E_{\mathrm{g}}^{\mathrm{BM}}=\frac{\hbar^{2}}{2 m_{\mathrm{vc}}}\left(3 \pi^{2} n_{\mathrm{e}}\right)^{\frac{2}{3}}
$$

where $m_{\mathrm{vc}}$ is the effective mass of the electron, $n_{\mathrm{e}}$ is the electron concentration, $\hbar$ is the reduced Planck constant. The decreasing concentration of free electron leads to a narrower band gap [33], so the sample under $15 \mathrm{sccm}$ flow rate embraces the highest band gap due to the lowest number of oxygen defects, and the sample under $0 \mathrm{sccm}$ flow rate has the lowest band gap because of the largest number of oxygen defects.

Therefore, the increasing number of oxygen defects will heavily decrease the band gap of thin film, resulting in a lower LIDT.

The surface morphologies of the $\mathrm{Sc}_{2} \mathrm{O}_{3}$ thin films under different oxygen flow rates are observed by AFM, which gives microscopic information about the surface structure of thin films and the plots of surface relief [34]. As shown in Figure $6 \mathrm{~b}, 15 \mathrm{sccm}$ sample possesses a very smooth surface. However, 
there are many defects on the surface of $0 \mathrm{sccm}$ sample. Defects will increase surface roughness and lead to a rough surface. This can be proven by Figure $6 f$, which represents that the root mean square of film surface roughness, $R_{\mathrm{q}}$, decreases with the decreasing of defects on the surface of samples. Compared with other samples, the $R_{\mathrm{q}}(0.393 \mathrm{~nm})$ of $15 \mathrm{sccm}$ sample is the lowest, but the $R_{\mathrm{q}}$ of $0 \mathrm{sccm}$ sample reaches up to $0.956 \mathrm{~nm}$. This result further proves the result of XPS representing that the number of oxygen defects heavily affects characteristics of films. In addition, it is interesting that there are similar steep descents on the left side of Figures $6 \mathrm{f}$ and $2 \mathrm{f}$, but the slopes are closer in absolute value in Figure $6 \mathrm{f}$ than in Figure 2f, which may be derived from the test errors. We will explore more closely the neighborhood of the minimum at $15 \mathrm{sccm}$ in future work.
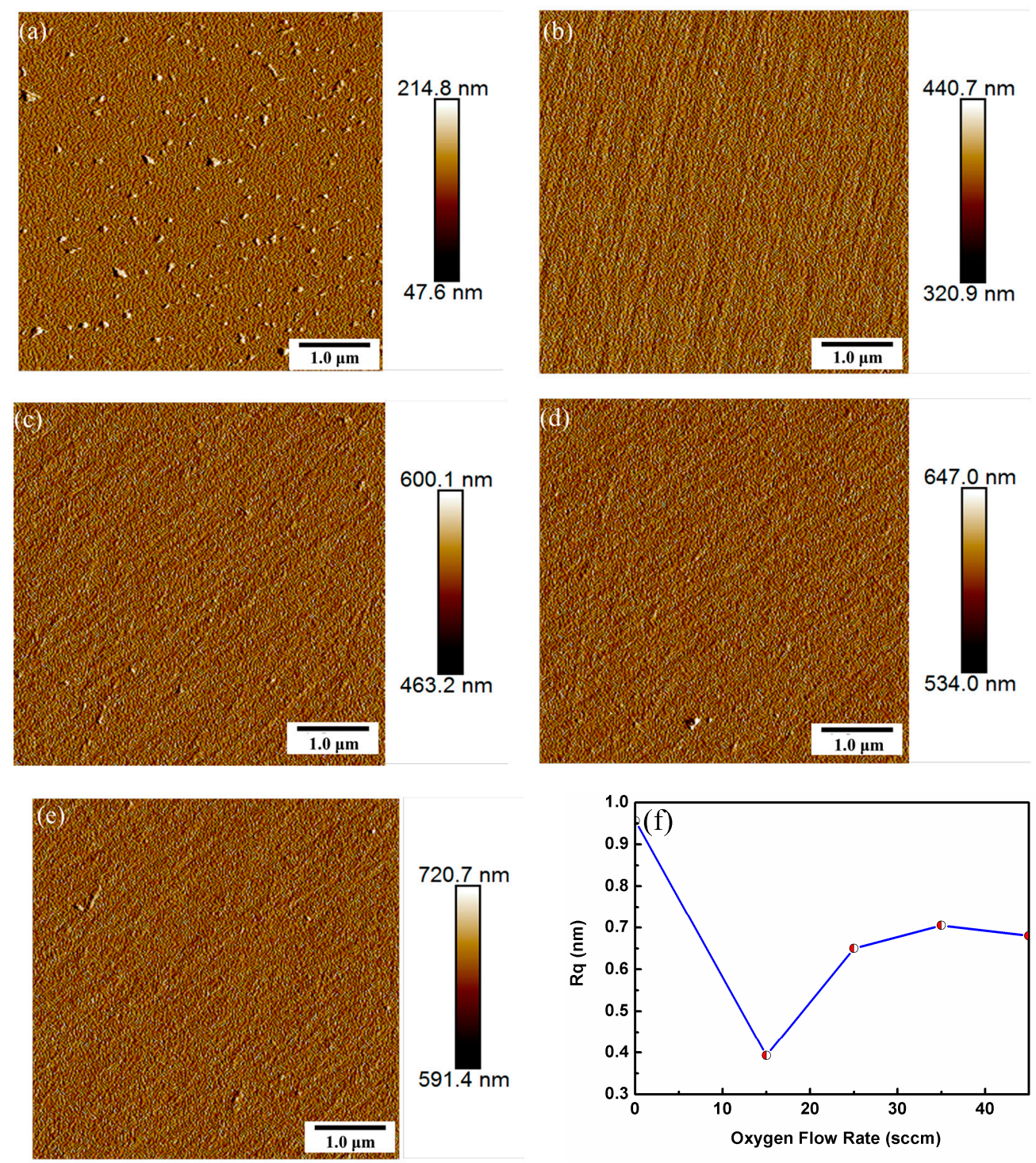

Figure 6. AFM images and $R_{\mathrm{q}}$ of $\mathrm{Sc}_{2} \mathrm{O}_{3}$ films deposited under different oxygen flow rates. (a) 0 sccm; (b) $15 \mathrm{sccm}$; (c) $25 \mathrm{sccm}$; (d) $35 \mathrm{sccm}$; (e) $45 \mathrm{sccm}$; (f) $R_{\mathrm{q}}$.

\section{Conclusions}

In conclusion, $\mathrm{Sc}_{2} \mathrm{O}_{3}$ thin films were prepared by IBS under different oxygen flow rates. The results provided insights into the complex relationships between oxygen defect and the characteristics of the deposited $\mathrm{Sc}_{2} \mathrm{O}_{3}$ films. When the oxygen flow rate was $0 \mathrm{sccm}$, the existence of numerous oxygen defects produced huge stress, which caused the positions of (222) and (440) peaks in $\mathrm{Sc}_{2} \mathrm{O}_{3}$ film to shift towards smaller angles. The worst transmittance, LIDT and surface roughness were also derived from 
the largest number of oxygen defects in $0 \mathrm{sccm} \mathrm{Sc}_{2} \mathrm{O}_{3}$ film. Moreover, the refractive index of $0 \mathrm{sccm}$ $\mathrm{Sc}_{2} \mathrm{O}_{3}$ film could not be obtained in the same way due to $\mathrm{F}$ and $\mathrm{F}^{+}$centers caused by oxygen vacancies. While the oxygen flow rate reached $15 \mathrm{sccm}, \mathrm{Sc}_{2} \mathrm{O}_{3}$ film had the best transmittance, refractive index, LIDT and surface roughness due to the lowest number of oxygen defects. The results indicated that oxygen defect played an important role in affecting the crystal phases, optical properties, LIDT and surface quality of $\mathrm{Sc}_{2} \mathrm{O}_{3}$ films. Limiting the oxygen flow rate was a necessary step of decreasing the number of oxygen defects.

Author Contributions: Conceptualization, P.K. and Y.P.; Methodology, Y.P.; Software, P.K.; Investigation, P.K. and Y.P.; Resources, J.Z. and P.M.; Data Curation, P.K.; Writing-Original Draft Preparation, P.K.; Writing-Review and Editing, Y.P. and J.Z.; Supervision, J.Z. and P.M.; Funding Acquisition, Y.P.

Funding: This work was funded by the National Natural Science Foundation of China (No. 51802295).

Acknowledgments: The authors gratefully acknowledge technical support from the Analytical \& Testing Center, Sichuan University.

Conflicts of Interest: The authors declare no conflict of interest.

\section{References}

1. Gschneidner, K.A.; Melson, G.A.; Youngblood, D.H.; Schock, H.H. Scandium its Occurrence, Chemistry, Physics, Metallurgy, Biology and Technology; Horovitz, C.T., Ed.; Academic Press: London, UK, 1975.

2. Rainer, F.; Lowdermilk, W.H.; Milam, D.; Hart, T.T.; Lichtenstein, T.L.; Carniglia, C.K. Scandium oxide coatings for high-power UV laser applications. Appl. Opt. 1982, 21, 3685-3688. [CrossRef] [PubMed]

3. Langston, P.F.; Krous, E.; Schiltz, D.; Patel, D.; Emmert, L.; Markosyan, A.; Reagan, B.; Wernsing, K.; Xu, Y.; Sun, Z. Point defects in $\mathrm{Sc}_{2} \mathrm{O}_{3}$ thin films by ion beam sputtering. Appl. Opt. 2014, 53, A276-A280. [CrossRef] [PubMed]

4. Xu, Y.; Abdulameer, M.R.; Emmert, L.A.; Day, T.; Patel, D.; Menoni, C.S.; Rudolph, W. Comparison of defects responsible for nanosecond laser-induced damage and ablation in common high index optical coatings. Opt. Eng. 2016, 56, 011019. [CrossRef]

5. Fu, X.H.; Commandre, M.; Gallais, L.; Mende, M.; Ehlers, H.; Ristau, D. Laser-induced damage in scandium, hafnium, aluminum oxides composites with silica in the infrared. In Proceedings of the Optical Interference Coatings 2013, Whistler, BC, Canada, 16-21 June 2013.

6. Fu, X.H.; Melninkaitis, A.; Gallais, L.; Kicas, S.; Drazdys, R.; Sirutkaitis, V.; Commandre, M. Measured nanosecond laser damage probabilities of niobia-silica and zirconia-silica mixtures coatings. In Laser-Induced Damage in Optical Materials, Proceedings of SPIE Laser Damage, Boulder, CO, USA, 23-26 September 2012; Exarhos, G.J., Gruzdev, V.E., Menapace, J.A., Ristau, D., Soileau, M.J., Eds.; SPIE: Bellingham, WA, USA, 2012.

7. Tamura, S.; Kimura, S.; Sato, Y.; Yoshida, H.; Yoshida, K. Laser-damage threshold of $\mathrm{Sc}_{2} \mathrm{O}_{3} / \mathrm{SiO}_{2}$ high reflector coatings for a laser wavelength of $355 \mathrm{~nm}$. Thin Solid Films 1993, 228, 222-224. [CrossRef]

8. Hollenbeck, J.L.; Buchanan, R.C. Oxide thin films for nanometer scale electron beam lithography. J. Mater. Res. 1990, 5, 1058-1072. [CrossRef]

9. Pike, G.E. AC conductivity of scandium oxide and a new hopping model for conductivity. Phys. Rev. B 1973, 6, 1572-1580. [CrossRef]

10. Heitmann, W. Reactively evaporated films of Scandia and yttria. Appl. Opt. 1973, 12, 394-397. [CrossRef] [PubMed]

11. Liu, G.; Jin, Y.; He, H.; Fan, Z. Effect of substrate temperatures on the optical properties of evaporated $\mathrm{Sc}_{2} \mathrm{O}_{3}$ thin films. Thin Solid Films 2010, 518, 2920-2923. [CrossRef]

12. Adelmann, C.; Lehnen, P.; Elshocht, S.; Zhao, C.; Brijs, B.; Franquet, A.; Conard, T.; Roeckerath, M.; Schubert, J.; Boissière, $\mathrm{O}$. Growth of dysprosium, scandium, and hafnium-based third generation high-k dielectrics by atomic vapor deposition. Chem. Vap. Depos. 2010, 13, 567-573. [CrossRef]

13. Putkonen, M.; Nieminen, M.; Niinistö, J.; Niinistö, L.; Sajavaara, T. Surface-controlled deposition of $\mathrm{Sc}_{2} \mathrm{O}_{3}$ thin films by atomic layer epitaxy using-diketonate and organometallic precursors. Chem. Mater. 2001, 13, 4701-4707. [CrossRef]

14. Klenov, D.O.; Edge, L.F.; Schlom, D.G.; Stemmer, S. Extended defects in epitaxial $\mathrm{Sc}_{2} \mathrm{O}_{3}$ films grown on (111) Si. Appl. Phys. Lett. 2005, 86, 051901. [CrossRef] 
15. Xu, Z.; Daga, A.; Chen, H. Microstructure and optical properties of scandium oxide thin films prepared by metalorganic chemical-vapor deposition. Appl. Phys. Lett. 2001, 79, 3782-3784. [CrossRef]

16. Kaichev, V.V.; Ivanova, E.V.; Zamoryanskaya, M.V.; Smirnova, T.P.; Yakovkina, L.V.; Gritsenko, V.A. XPS and cathodoluminescence studies of $\mathrm{HfO}_{2} / \mathrm{Sc}_{2} \mathrm{O}_{3}$ and $\left(\mathrm{HfO}_{2}\right)_{1-x}\left(\mathrm{Sc}_{2} \mathrm{O}_{3}\right)_{x}$ films. Eur. Phys. J. Appl. Phys. 2013, 64, 10302. [CrossRef]

17. Liu, C.; Chor, E.F.; Tan, L.S.; Du, A. Epitaxial growth of $\mathrm{Sc}_{2} \mathrm{O}_{3}$ films on $\mathrm{GaN}$ (0001) by pulsed laser deposition. J. Vac. Sci. Technol. B 2007, 25, 754-759. [CrossRef]

18. Feijoo, P.C.; Pampillón, M.A.; Andrés, E.; Lucía, M.L. Optimization of scandium oxide growth by high pressure sputtering on silicon. Thin Solid Films 2012, 526, 81-86. [CrossRef]

19. Hays, D.C.; Gila, B.P.; Pearton, S.J.; Kim, B.J.; Ren, F.; Jang, T. Band offsets in $\mathrm{Sc}_{2} \mathrm{O}_{3} / \mathrm{ZnO}$ heterostructures deposited by RF magnetron sputtering. J. Vac. Sci. Technol. B 2015, 33, 051218. [CrossRef]

20. Alexandr, B.; Kęstutis, J.; Lukas, C.; Romanas, S.; Sandra, S.; Vitalija, J.; Simonas, K. Correlation between stoichiometry and properties of scandium oxide films prepared by reactive magnetron sputtering. Appl. Surf. Sci. 2018, 427, 312-318.

21. Wang, S.; Ma, P.; Pu, Y.; Qiao, Z.; Zhang, M.; Lu, Z.; Peng, D. Effect of oxygen flow on the structure and optical properties of the $\mathrm{Gd}_{2} \mathrm{O}_{3}$ optical films. In 8th International Symposium on Advanced Optical Manufacturing and Testing Technologies: Advanced Optical Manufacturing Technologies, Proceedings of Eighth International Symposium on Advanced Optical Manufacturing and Testing Technology (AOMATT2016), 26-29 April 2016, Suzhou, China; Jiang, W., Yang, L., Riemer, O., Li, S., Wan, Y., Eds.; SPIE: Bellingham, WA, USA, 2016.

22. Krous, E.; Patel, D.; Langston, P.; Menoni, C.; Markosyan, A.; Route, R.; Fejer, M.; Nguyen, D.; Emmert, L.; Rudolph, W. Scandium oxide thin films deposited by dual ion beam sputtering for high-power laser applications. In Proceedings of the Optical Interference Coatings 2010, Tucson, AZ, USA, 6-11 June 2010.

23. Payne, B.P.; Biesinger, M.C.; McIntyre, N.S. The study of polycrystalline nickel metal oxidation by water vapour. J. Electron. Spectrosc. Relat. Phenom. 2009, 175, 55-65. [CrossRef]

24. Belosludtsev, A.; Houska, J.; Vlcek, J.; Haviar, S.; Cerstvy, R.; Rezek, J.; Kettner, M. Structure and properties of Hf-O-N films prepared by high-rate reactive HiPIMS with smoothly controlled composition. Ceram. Int. 2017, 43, 5661-5667. [CrossRef]

25. Musil, J.; Zenkin, S.; Kos, S.; Cerstvy, R.; Haviar, S. Flexible hydrophobic ZrN nitride films. Vacuum 2016, 131, 34-38. [CrossRef]

26. Musil, J.; Baroch, P.; Vlcek, J.; Nam, K.H.; Han, J.G. Reactive magnetron sputtering of thin films: Present status and trends. Thin Solid Films 2005, 475, 208-218. [CrossRef]

27. Klein, C. How accurate are Stoney equation and recent modifications. J. Appl. Phys. 2000, 88, 5487-5489. [CrossRef]

28. Serpone, N. Is the band gap of pristine $\mathrm{TiO}_{2}$ narrowed by anion- and cation-doping of titanium dioxide in second-generation photocatalysts. J. Phys. Chem. B 2006, 110, 24287-24293. [CrossRef]

29. Osuwa, J.C.; Oriakuand, C.I.; Kalu, I.A. Variation of optical band gap with post deposition annealing in CdS/PVA thin film. Chalcogenide Lett. 2009, 6, 433-439.

30. Adam, A.; Lilov, E.; Ibrahim, E.; Petkov, P.; Panina, L.; Darwish, M. Correlation of structural and optical properties in as-prepared and annealed $\mathrm{Bi}_{2} \mathrm{Se}_{3}$ thin films. J. Mater. Process. Technol. 2019, 264, 76-83. [CrossRef]

31. Fursenko, O.; Bauer, J.; Lupina, G.; Dudek, P.; Lukosius, M.; Wenger, C.; Zaumseil, P. Optical properties and band gap characterization of high dielectric constant oxides. Thin Solid Films 2012, 520, 4532-4535. [CrossRef]

32. Hamberg, I.; Granqvist, C.G.; Berggren, K.F.; Sernelius, B.E.; Engstrom, L. Band gap widening in heavily Sn-doped $\mathrm{In}_{2} \mathrm{O}_{3}$. Phys. Rev. B 1984, 30, 3240-3249. [CrossRef]

33. Choudhury, B.; Choudhury, A. Lattice distortion and corresponding changes in optical properties of $\mathrm{CeO}_{2}$ nanoparticles on Nd doping. Curr. Appl. Phys. 2013, 13, 217-223. [CrossRef]

34. Eskandari, F.; Kameli, P.; Salamati, H. Effect of laser pulse repetition rate on morphology and magnetic properties of cobalt ferrite films grown by pulsed laser deposition. Appl. Surf. Sci. 2019, 466, 215-223. [CrossRef]

(C) 2019 by the authors. Licensee MDPI, Basel, Switzerland. This article is an open access article distributed under the terms and conditions of the Creative Commons Attribution (CC BY) license (http://creativecommons.org/licenses/by/4.0/). 